\title{
The March 2006 Solar Eclipse in Nigeria: Mysteries and Virtues
}

\author{
K. A. Aderogba (Mrs), \\ Faculty of Social and Management Sciences. \\ Tai Solarin University of Education. \\ Ijebu- Ode, Nigeria \\ M. A. Obafemi \\ Faculty of Social and Management Sciences. \\ Tai Solarin University of Education. \\ Ijebu- Ode, Nigeria \\ B. A. Ogunyemi. \\ Faculty of Social and Management Sciences. \\ Tai Solarin University of Education. \\ Ijebu- Ode, Nigeria
}

Accepted: November 23, 2011 Published: January 02, 2012

Doi:10.5296/ijld.v2i1.1217 URL: http://dx.doi.org/10.5296/ijld.v2i1.1217

\begin{abstract}
.
The earliest known reference to eclipse goes back to the $21^{\text {st }}$ Century B.C. In Nigeria, it dates to 1898; and before 2006, the last Solar Eclipse was in 2001. During, before and after the 2006 celestial phenomenon, radio and television programmes on the eclipses were listened to. Also newspapers, journals, magazines and books on Astronomy and celestial bodies were extensively and generously read. The awesome phenomenon began with the sky getting hazy as early as 09.40 Hours. It was as if there was going to be rain. It was followed by a thick darkness that normally precedes heavy rain. The temperature dropped. It was Partial Eclipse in Ibadan, Abuja, Minna, and
\end{abstract}


Lagos, Abeokuta and substantial parts of the West; and to the middle belt and North West. At Kastina, Gusau, Kazaure, Isah, Shaki, Tede and Sepeteri, it was Total Eclipse. The region that experienced the total eclipse falls within the same ranges of Longitude and Latitudes. By 10.35 Hours, it was all over; the sky became clear and scorching sun took over. The greatest experience was in Shaki, Oyo State: It was total Eclipse. Foreign tourists, journalists and government functionaries traveled from far and near to watch and experience the eclipse in Nigeria. The occurrence of the solar eclipse marked the end of the population and housing census in Nigeria; Charles Taylor, the Liberian Warlord was arrested and deported to his country; and Governor Gbenga Daniel of Ogun State (Nigeria) marked the Golden Jubilee of his Birthday.

Key Words: $\quad$ Solar Eclipse, Mysteries, Virtues, Nigeria.

\section{PREAMBLE}

The earliest references to eclipses for which dates can be established with reasonable confidence go back to the $21^{\text {st }}$ century B.C. (Link, 1967). According to him, there are records on the series of astrological tablets from Ur known as Enuma Anu Enlil. Several of these texts contain lunar eclipse Omina - warning of disasters that might follow an eclipse based on past coincidences between celestial and terrestrial occurrences. Some of the Omina are so detailed that they are clearly based on observation of a specific eclipse. The following is an extract from Tablet 20 of the series as quoted by Encyclopaedia Britannica (2004):

If a Simanu (Lunar month III) an eclipse occurs on day 14, the [moon -] god in his eclipse is obscured on the east side above and clears on the west side below, the north wind blows, [the eclipse] commence in the first watch of the night and it touches the middle watch... by this the [moon-] god gives a decision for Ur and the King of Ur will see a famine, there will be many deaths, the King of Ur will be wronged by his sons; the son who has wronged his father, the Sun - god will catch him, and he will die at the burial of his father. A son of the King who was not named for kingship will then occupy the throne.

From a careful investigation of the historical and astronomical circumstances among the ancient Babylonians, and according to Encyclopaedia Britannica (2004) and Stephenson (1982), it has shown that the eclipse referred to here is very likely to have been associated with 
the murder of Shulgi by his son and accession of Amer - sin. The most probable date for the eclipse is April 4, 2094 BC. A further eclipse (lunar) 42 years later regarded as signaling the destruction of Ur has been dated to April 13, 2053 BC, (Encyclopaedia Britannica, 2004).

Also, according to a long established history and tradition among the Chinese, the history of astronomy in ancient China could be traced back to before $2000 \mathrm{BC}$. The earliest surviving relics that are of astronomical significance date from nearly a millennium later, however. The An-Yang oracle bones (inscribed turtle shells, ox bones, and so forth) of the Shang dynasty (C. 1550 - 1050 BC), which have been uncovered near An - Yang in north eastern China, record several eclipses of both the Sun and the Moon. The following report documented in Encyclopaedia Britannica (2004) is an example:

On day Kuei - yu [the $10^{\text {th }}$ day of a 60 - day cycle]:

"The sun was eclipsed in the evening; is it good?"

On day Kuei - yu it was inquired:

"The sun was eclipsed in the evening is it bad?"

Again, this provides clear evidence that eclipses were regarded as omens at this early period. Such a belief was extremely prevented in China during later centuries, (Needham, 1959). The term translated here as "eclipse" (Chih) is the same as the word "eat." The Shang people thought that some monsters were actually devouring the Sun or Moon during an eclipse. Not until many centuries later was the true explanation known; but by then the use of the term Chih was firmly established to describe eclipse, and so it continued throughout Chinese history. As the year in which an eclipse occurred is never mentioned on the preserved oracle bones (many of which are mere fragments), dating of these observations by astronomical calculation has proved extremely difficult, remarked Eliot (1921 p. 801).

There are similar historical documentation and references among the Assyrians, Jewish, Greeks, Romans, Medieval European and Medieval Islamic nations. 
The eclipses are used for chronological and astronomical purposes: No one system of dating has been continuously in use since an ancient time, although some, like the Olympiads persisted for many centuries, Said et al (1989).

By and large, what are myths and virtues of the experiences - in Nigeria? The objectives of this piece is to explain the concept of eclipses particularly the Solar Eclipse, trace the history; describe the March 29, 2006 Eclipse as it was experienced across the nation; demystify the concept and document for geo-historical record purpose the virtues associated with the eclipse in Nigeria.

The paper is based on literature search: Encyclopaedia Britannica provides the materials from which the conceptual background was drawn. Interviews were conducted with the principal officers in the Federal Ministry of Science and Technology. A Director in the National Space Research and Development Agency (NASRDA), Abuja was interviewed. Members of the public were interviewed based on their experiences of the past and March 2006 Solar Eclipse in Nigeria and or else where in the world. Respondents were drawn from all the state capitals of the federation. Other towns and cities included are Oyo, Ijebu-Ode, Igbo-Ora, Kazaure, Ilesha, Gusau, Shaki, Sepeteri, Asah Koko and Nnewi. Travelers on the roads, in the air and on water at the period were interviewed. The researchers listened to radio and television discussions, debates, news and announcements particularly in the week of the March Eclipse.

Similarly, all columns, articles and reports about the eclipses were read in the news papers, magazines and periodicals of that week and month of the eclipse. Large numbers of Journal Articles were read. GSM phones played significant roles in data collection. Very robust data/information, were gathered about the eclipse generally and eclipse of the sun in particular. Substantially, very vast facts, figures and information about the last March $29^{\text {th }}$ Solar Eclipse in Nigeria became available too. The paper is in seven parts.

\section{THE LOGICAL ENTITIES OF ECLIPSES}


In astronomy, complete or partial obscuring of a celestial body by another is called Eclipse. An eclipse occurs when three celestial objects become aligned. The sun is eclipsed when the moon comes between it and the Earth; the moon is eclipsed when it moves into the shadow of the Earth cast by the Sun. Eclipse of natural or artificial satellites of a planet occurs as the satellites move into the planet's shadow. The two component stars of an eclipsing binary star move around each other in such a way that their orbital plane passes through or very near Earth, and each star periodically eclipses the other as seen from the Earth.

When the apparent size of the eclipsed body is much smaller than that of the eclipsing body, the phenomenon is known as an occultation. Examples are the disappearance of a star, nebula, or planet behind the moon, or the vanishing of a natural satellite or space probe behind some body of the solar system. A transit occurs when, as viewed from the Earth, a relatively small body passes across the disk of a larger body, usually the sun or a planet, eclipsing only a very small area: Mercury and Venus periodically transit the sun, and a satellite may transit its planet.

Totality at any particular solar eclipse can only be seen from a relatively narrow belt on Earth. The first contact designates the moment when the disk of the moon, invisible against the bright sky background, just touches the disk of the sun. The partial phase of the eclipse then begins, as a small indentation in the western rim of the Sun becomes noticeable. The dark disk of the Moon now gradually moves across the Sun's disk, and the bright area of the Sun is reduced to a crescent. The sunlight, shining through gaps in foliage and other small openings, is then seen to form little crescents of lights that are images of the light source, the Sun. Toward the beginning of totality, the direct light from the Sun diminishes very quickly and the colour changes. The sky becomes dark but along the horizon, the Earth's atmosphere still appears brightly because the umbra of the Moon's shadow on the Earth extends over a rather narrow region. The scattered light coming in from a distance beyond this region produces weird effects. Man, birds, and other animals react with fear; birds may go to roost as they do at sunset, (Green, 1947 and Encyclopaedia Britannica 2004). 
As the tiny, narrow crescent of sunlight disappeared, little bright specks remain where depressions in the Moon's edge, the limb, are last to obscure the Sun's limb. The specks are known as Baily's beads, after $18^{\text {th }}$ century English astronomer Francis Baily, who first drew attention to them. The beads vanished at the moment of second contact, when totality sets in. This is the climax of the eclipse. The reddish prominences and chromospheres of the sun, around the moon's limb, can now be seen. The brighter planets and stars become visible in the sky. The white corona extends out from the sun to a distance greater than the sun's diameter, at which point, it fades completely. The temperature in the path of totality falls by some degrees. The light of totality is much brighter than that of the Full Moon but is quite different.

The moment the third contact approaches, at which time many of the phenomena of a second contact appear again in reverse order. Suddenly, the first Baily's bead appears, now on the other side of the Moon. More beads of light follow, the Sun's crescent grows again the corona disappears, daylight brightens, and the stars and planets fade from now. The thin crescent of the sun gradually widens and about one and a quarter hours later, the eclipse ends with fourth contact, when the last encroachment made by the Moon on the Sun's rim disappears.

Mucke and Meeus (1983) have asserted that during the partial phase, both before and after totality, "it is absolutely essential to protect the eyes against injury by the intense brilliance of the Sun." It should never be viewed directly except through "strong filters, a dark smoked glass, or a heavily flogged photographic plate or film."

When totality is imminent and only a small crescent of the sun remains, the so-called shadow bands can often be seen on plain - coloured surface, such as open floors and walls. These are striation of light and shade, moving and undulating, several centimeters wide. Their velocity and direction depend on air currents at various heights, as they are caused by refraction of sunlight by small in-homogeneities in the Earth's atmosphere (Mucke and Meeus, 1983). A similar phenomenon is the projection of water waves on the bottom of a sunlit swimming pool.

However, above is enough explanation and exploration on the concept of eclipse and eclipses. What were the similarities or otherwise between the concept explained and what happened and 
experienced on Wednesday 29th March 2006 are contained in the next section of the paper. Emphasis is on the Nigerian territory.

\section{MARCH 29 2006 ECLIPSE}

This was the $5^{\text {th }}$ in about 106 years. Records show that the first was in 1896, second in 1947 , then 1959 and 2001 before the March $29^{\text {th }}$ episode. Hitherto $29^{\text {th }}$ March, 2006, there have been announcements on televisions, radio and newspapers. Organizations, academic and research institutions, government ministries and parastatals, religious bodies (particularly Christians and Muslims), families and groups also issued out circulars and or make pronouncements about the expected eclipse (of the sun). The announcements were in respect of the time of occurrence, its physical nature and appearance, how to watch it, its significance to life time; and not to fear its appearances. Residents were directed not to watch it with eyes directly. But to view it (the eclipse) with the aid of filters, improvised pin holes, cardboards, sunglasses etc. For instance, earlier, the Federal Ministry of Science and Technology in a memorandum presented to the Federal Executive Council alerted the nation of the eclipse. In other words, it was much expected in some major cities and towns across the nation.

The awesome phenomenon began with the sky getting hazy as early as 09:35 Hours. It was as if there was going to be rain particularly in those areas where the eclipse was total. It was followed by a thick darkness that normally precedes heavy rain. The occurrence cut across the nation but with remarkable differences at some locations. That is the experience differs from one location to another. To the North West of the country: Katsina, Gusau, Kazaure, Kano and Isah, among others, total eclipse was observed. See Figures 1.and 2. showing total eclipse as observed at Isah and Kasaure. In the western part of the country, Abeokuta and Ibadan, partial eclipse was experienced. The entire Lagos metropolis experienced partial eclipse. To the North of South West is Shaki and it was a total eclipse that was viewed. See Fig. 3; and Table I showing the different types of solar eclipse viewed in different parts of Nigeria. Figs. 4, 5 and 6 each shows the partial eclipse as observed in Lagos, Ibadan and Abuja. 
Particularly as widely monitored and documented at Shaki, the disk of the moon first touched the disk of the sun. A small indentation in the western rim of the sun became noticeable. The dark disk of the moon quickly moved across the sun's disk. The bright area of the sun also got quickly to a crescent. The sky changed taking on a humid and dark hue. Little crescent of light (image of the light from the sun) was noticeable shinning through the gaps in foliage and other small openings. The direct light (from the sun) diminished very quickly. The colour changed. The sky became dark. The air became cool, the eerie half light descended over the light. Though, the atmosphere still appeared slightly bright. The light was scattered and it produced rear effects but as the timing narrow crescent was disappearing, little bright specs remained where depressions in the moon's was last to obscure the sun's limb. Totality set in. The beads vanished. The total eclipse, the climax of the eclipse "arrived." The sky got hazy, clothed the air with total darkness leaving all the people within the points of total eclipse to grope in the dark. But it was a beautiful sight to behold. There was reddish prominence and chromospheres of the sun around the Moon's limb became very conspicuous.

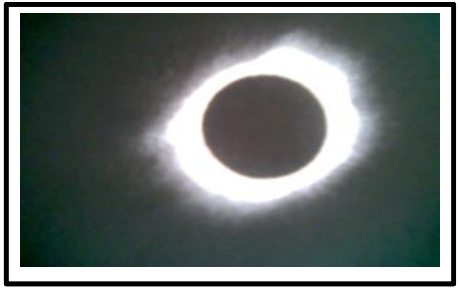

Fig. I

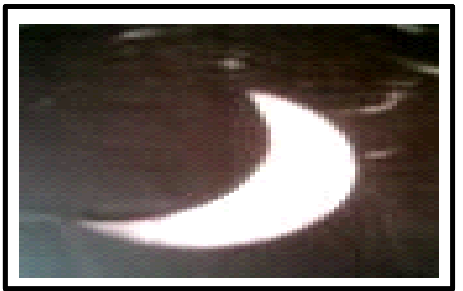

Fig. IV

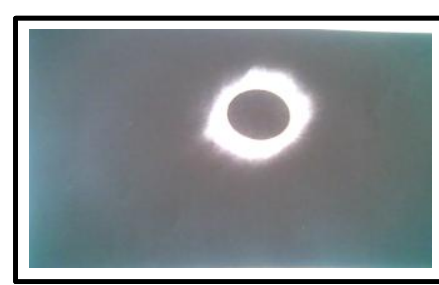

Fig. II

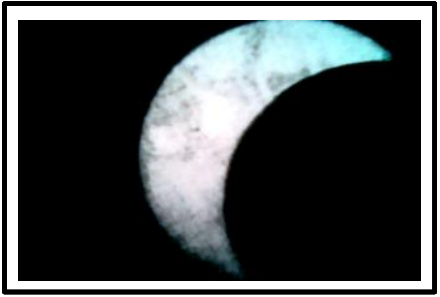

Fig. V

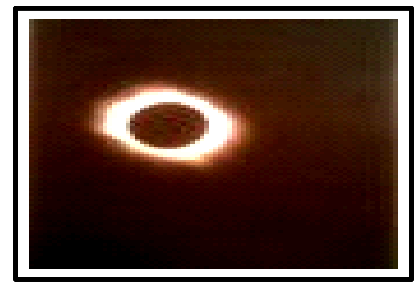

Fig. III

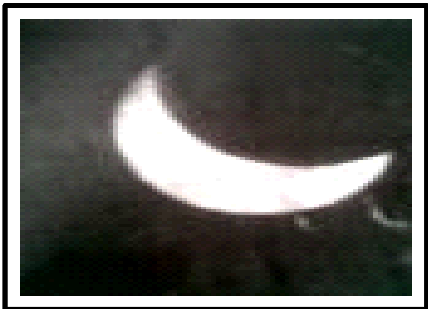

Fig. VI

Figs I, II, III Total Eclipse at Saki, Isah and Kasaure and IV, V, and VI Partial Eclipse in Lagos, Abuja and Abeokuta respectively. 
Table I: Types of Eclipse Viewed in Different Parts of Nigeria

\begin{tabular}{|c|c|c|}
\hline Town/City & \begin{tabular}{|lll} 
Average & Time & of \\
Occurrence & & \\
\end{tabular} & Type \\
\hline Katsina & $09: 35-10: 14$ & Total \\
\hline Gusau & $09: 55-10: 21$ & Total \\
\hline Kazaure & $09: 58-10: 22$ & Total \\
\hline Kano & $09: 35-10: 21$ & Partial \\
\hline Makurdi & $09: 45-10: 14$ & Partial \\
\hline Isah & $09: 42-10: 19$ & Total \\
\hline Sokoto & $09: 44-10: 21$ & Partial \\
\hline Abeokuta & 09:38 - 10:06 & Partial \\
\hline Ijebu-Ode & $09: 36-10: 14$ & Partial \\
\hline Ibadan & $09: 34-10: 25$ & Partial \\
\hline Lokoja & $09: 38-10: 22$ & Partial \\
\hline Oyo & $09: 32-10: 18$ & Partial \\
\hline Shaki & $09: 35-10: 18$ & Total \\
\hline Ado-Ekiti & $09: 42-10: 12$ & Partial \\
\hline Tede & $09: 35-10: 25$ & Total \\
\hline Sepeteri & 09:38 - 10:18 & Total \\
\hline Akure & 09:46 - 10:20 & Partial \\
\hline Iwo & $09: 32-10: 15$ & Partial \\
\hline Lagos & $09: 38-10: 24$ & Partial \\
\hline Minna & $09: 34-10: 15$ & Partial \\
\hline Assaba & $09: 35-10: 26$ & Partial \\
\hline Onitsha & $09: 35-10: 24$ & Partial \\
\hline Owerri & $09: 42-10: 15$ & Partial \\
\hline Benin City & $09: 40-10: 22$ & Partial \\
\hline Abuja & $09: 45-10: 12$ & Partial \\
\hline
\end{tabular}


Source: Field Work

The temperature fell by some degrees. There were different reactions from different groups and individuals. Plants and animal even reacted differently. That stars appeared cannot be confirmed by this work, but an account of the different reactions from different parts of the country is as contained in the next section of this paper. Suffice it to mention here that birds were few around at about that short period of time, animals: sheep, goat and dogs were not active either.

But suddenly, what was referred to as Baily's bead appeared again, that is on the other side of the moon. More beads of light followed and the sun's crescent grew again. There appeared again a brighter hue. The corona disappeared, daylight brightened. The thin crescent of the sun gradually widened. There was no more encroachment made by the moon, and the sun's rim disappeared. Then, it all ended. The whole episode lasted for just about 4,250 seconds on the average. In principle, therefore, Tede, Sepeteri, Shaki ,Kazaure and Gusau fell within the umbra: The Sun's disk appeared completely covered by the disk of the moon. See Table I and Figs. 1-6 above.

In the other parts, where the eclipse was noticed - the middle belt - Minna, Lokoja, Makurdi, Abuja and to South West - Lagos, Ibadan including Ago-Iwoye and Ijebu-Ode, it was partial eclipse. See Table I. These locations fell within the umbra and the moon's disk appears projected against the sun's disk only partly overlapping it. These locations are within the penumbra: The moon's disk appeared projected against the disk of the sun - it overlapped it partially.

In the far eastern part of the country, the experience was like mere imagination i.e. as from across the River Niger. But it could be best described as partial.

The time of occurrence do not differ significantly from one location to another: All through, it was between 09:34 Hours and 10:25 hours. That is, in all the locations in Nigeria, it does not last beyond 10:25 Hours anywhere within the country - partial and or total, incidentally: 
- the day and time of occurrence coincided with the harmattan haze. It thus made it slightly difficult to distinguish between the time it started, and when it rounded-up; and

- Tede, Sepeteri, Shaki, Kazure, Gusau, Isah fall within the same range of longitude and latitudes - between longitude $3.04^{\circ}$ and $8.20^{\circ}$ East, and Latitude $8.21^{\circ}$ and $13.15^{0}$ North.

Outside Nigeria, the same eclipse of the sun was experienced in Ghana, Republic of Togo, Benin Republic, Chad, Niger Republic and Libya. It cast the interesting shadow across Africa even tracked on to the Middle East: It actually stretched from Eastern Brazil (South America), across the Atlantic (Ocean) to North Africa, then in the Middle East, Central Asia, West China and Mongolia, (Babafemi, 2006). According to him, and from satellite reports, the longest view was at Wao Namus settlement (Libya) near the Chadian border (about 2,000 km) south of Tripoli. As soon as the outline of the moon began to creep across the face of the sun, crowds turned out on the beaches, streets, on balconies, roof tops, outside office premises, on fields, besides roads and in front of churches and mosques. Foreign tourist and journalists, traveled from far and near to Shaki (Nigeria) to see the eclipse. The reactions were very diverse and marvelous.

\section{EXPERIENCE OF NIGERIANS AND MYSTERIES:}

Fear, excitement and anxiety gripped many Nigerians few hours before the appearance. There was apprehension about what might be the effect of the phenomenon. It was an unusual experience to very many. The eventful day was characterized by unusual enthusiasm from jubilant Nigerians who openly expressed appreciation to God for being alive to witness one of nature's mysteries. Open - air Interdenominational prayers led by State Governors and Clergymen and women were held in some states. At Shaki, people viewed, and watched with enthusiasm. There were shouts of "God is great" this shows the greatness of nature. It is very beautiful... never experienced anything like this before" that is, among the viewers. There was cries of "Hallelujah and praise the Lord" as viewers were shouting and clapping in excitement 
and sharing protective glasses. Drivers and motor bike operators hooted their horns in the dark that closely appeared like 19:30 Hours to 19:45 Hour of ordinary day in Nigeria. A motor bike operator exclaimed and expressed his amazement thus:

"It is amazing, the best experience of my life.

I never imagined I would see this, it is a wonderful experience"

To those that have experienced it before, "the eclipse is the coolest natural phenomenon ever experienced in life, just like this." A young Lady Pastor explained:

"It marked my birthday; and it shows the greatness of God in my life"

Some Muslim fateful claimed that the eclipse disappeared after few minutes as a manifestation of God's immense influence and power over the world.

Road travelers between Lokoja and Abuja, Lagos and Ibadan, Enugu and Port-Harcourt and Kaduna and Kano stopped, parked and watched "the uncommon celestial phenomenon." The explanation of the phenomenon to the villagers dwelling along the road sides between Lagos-Ibadan Expressway did not make any difference: Their ignorance were so evident - it was an impending rain that wanted to fall but stopped progressing.

Governors, commissioners and government functionaries, politicians and security operatives broke protocols and momentarily abandoned their schedules, assignments and engagements to watch it. One of these is the government and people of Oyo State. The highest ruling body in Nigeria, the Federal Executive Council led by the Vice President, interrupted the Council meeting to watch the Eclipse of the Sun.

At the fore court of the Presidential villa, in the midst of the Federal Executive Council members he remarked:

It is quite interesting. We are not expected to see total eclipse here at Abuja but I think there are other places in the country where they are expected to see a total eclipse of the sun...I cannot remember...when I was a kid they used to 
lock us up in the room and would not allow us to come out...wish everybody is aware of this...so that they can come out and see how it is. But I know that there are lot of superstitious belief surrounding this."

The Federal Ministry of Science and Technology provided the Council members special protective spectacles with which they viewed the eclipse. Aside these, the following stand out as responses, comments and reactions to the celestial phenomenon:

- while schools, shops, offices etc. closed temporarily for fear of the unknown, and some were excited to see the once in a life time precious moment of change in configuration of weather with the reduction of the intensity of the sun, others were very indifferent, oblivious and ignored the event;

- $\quad$ panic gripped parents particularly mothers who ran helter smelter to look for their children and wards apparently out of fear arising from "the sudden change in weather."

- Some communities nick-named it as "dance" between the moon and the sun while some call it a "fight" between the two bodies;

- About five children fainted in Gusau, Zamfara state out of fear and panic;

- Cities and towns where total eclipse was experienced were thrown into darkness as if there was going to be heavy rain;

- Commercial activities were temporarily paralysed as long as it lasted across certain states of the federation;

- Resident of cities and towns in most places trooped out in large number and in excitement as soon as the eclipse began to show its signs;

- Like legislators, government functionaries and politicians, factory workers and health workers were equally found outside their offices and factories having a glimpse of the eclipse;

- It was excitement filled with apprehension at some other places e.g. at Abeokuta (Ogun State Capital) about their safety while the eclipse lasted;

- Following from above too, many residents of some cities and towns were skeptical 
about going about their normal business. Those that summoned courage, particularly commercial taxi drivers and motor bike operators made brisk businesses before and while the experience lasted.

- It was topical issues among groups of friends, families and associations discussing the fight between the moon and the sun.

- The State Police Commands maintained surveillance in some states to prevent break down of law and order as many citizen had earlier believed that the end of the world had come or was near;

- Poor visibility that heralded the day turned into total darkness that compelled motorists and cyclist to switch on their head lamps;

- Residents of Katsina and Kazaura and environs woke up to a cold and dusty day on the Wednesday contrary to the hot and bright weather of the previous day (Tuesday);

- In Isah village of Sokoto state, residents remained in-door during the time it lasted;

- In some cities and towns, some Christians continually praised God with the words "Alleluyah, Praise God, God is Great," and the Muslims, "Allah Akbar." Muslim fateful went into the mosques nearest to them and observed some moments of silence with Allah according to Islamic injunction. Similarly, some Christians converged and organized vigil the previous night for prayer and sober reflection; and;

- A Muslim scholar with Islamic Learning Centre (Kaduna) described the phenomena as a sign of warning from God.

The spectacular mystery momentarily saw the sun completely covered by the moon at the total eclipse. A development that cast complete darkness on Saki, Kazaure and Gusau environs as well as partial darkness in other parts of the states and the nation at large. See Table I. It was hundred of thousands of people including the Oyo State Governor, his Deputy, all members of his cabinet, tourist, journalists and jubilant crowd that watched the unusual spectacle at Shaki and all over the federation. Table II shows the number of eclipses predicted to take place between $20^{\text {th }}$ and $25^{\text {th }}$ centuries. The highest numbers, 248 each will be in $2201-2300$ and 
$2301-2400$ centuries. The lowest will be in this century $2001-2100$, that is, 224 eclipses only. There were 228 eclipses in the last, $1901-2000$.

Table II: Predicted Eclipses to Take Place Between $20^{\text {th }}$ and $25^{\text {th }} . \square$ centuries

\begin{tabular}{|l|l|l|}
\hline Date & No of Eclipse & No of Central Eclipse \\
\hline $1901-2000$ & 228 & 145 \\
$2001-2100$ & 224 & 144 \\
$2101-2200$ & 235 & 151 \\
$2201-2300$ & 248 & 156 \\
$2301-2400$ & 248 & 160 \\
$2401-2500$ & 237 & 153 \\
\hline
\end{tabular}

Source: Encyclopaedia Britannica (2004) Deluxe Edition CD-ROM. Encyclopaedia Britannica library, UK.

The central eclipse will be highest in number (160) between 2301 and 2400; and it will be lowest in this century, 144 only. However, what are the significances of these in the socio-economic and geo-historical perspectives of Nigeria and Nigerians.

\section{HOW IT WAS VIEWED:}

Not all people in the country were aware as $3 \%$ of the respondents interviewed across the nation wondered when it came and went. The time was so short; and the appearance was not significant far East.

Various materials were devised to view the eclipse. Interestingly, as the eclipse is not a common phenomenon to any particular nation, apparatus for watching it was not found manufactured and displayed on any shelf neither for sale in any store nor for use in any scientific research laboratory. However, the National Space Research and Development Agency had earlier taken delivery of over 500,000 special filters of which the Federal Government sent 10,000 to Oyo State. But the commonly improvised in offices, schools, markets, mechanic villages, open fields, homes, motor parks, abattoirs, factories etc. includes:

- $\quad$ shredded black polythene material with clean surface; 
- Plane transparent glass with the reversed side painted black with candle flame;

- Sunglasses of various shades, shapes, sizes and makes;

- Improvised cardboards with pin-holes on it;

- Many residents watched it directly from bowls of water outside their residences;

- Similarly, communities, and farmers watched it on the surface of stream water, in ponds and such standing waters.

- Welder's eye shields were used by welders and those that were around them. The eye shields were passed from one person after the other as it lasted; and

- Against experts' advice, many took the risk and looked at the sky directly to watch the eclipse.

It is no longer a mystery: Many saw it; updated their knowledge and understanding. Above all, it is of great virtue to the nation at large and individual communities, families and persons in particular. These probably explain why both old and young temporarily abandoned their chores and businesses to watch the eclipse.

\section{THE VALUE AND VIRTUES:}

The Solar eclipse experienced on $29^{\text {th }}$ March 2006 between the hours of 09:40 and 10:25 made history in Nigeria. It was quite interesting. Many cannot remember ever watched it before and there are likelihood that many will never see it again as the next one is speculated to occur 2034. The one of March $29^{\text {th }} 2006$ was the fifth of such occurrence to be witnessed in Nigeria. The event recreated and entertained individuals and groups; and history was made. Specifically, the following will go down into the history and archives of Nigeria:

- The eclipse occurred and it was observed on the Wednesday of the week Nigeria completed the 2006 Population and Housing census exercise.

- It was the second time the government of Chief Olusegun Obasanjo will witness eclipse of the sun (the first being 2001) 
- It marked the date when Charles Taylor, the Liberian War Lord (and former Liberian President) was arrested in Borno State, Nigerian - Cameroon border, and was extradited to Liberia.

- $\quad 29^{\text {th }}$ March 2006 marked great days and dates for many communities, families and individuals. There were births and deaths; silver and golden jubilee etc. were marked;

- Governor Gbenga Daniel of Ogun State, Nigeria was 50 years old and celebrated the Golden Jubilee of his Birthday during the week;

- Some Nigerians, in different ways made brisk businesses while the episode lasted (e.g. motor bike and taxi operators doubled their fares and rates, and welders and other opportunists used their goggles, sunshades, meters etc. for commercial purposes;

- Shops, commercial activities and most other businesses including government businesses temporarily got paralyzed;

- The excited Nigerians, witnessed first hand, the beauty of a total or a partial solar eclipse, and it was described by many as the most awe-inspiring event nature can offer;

- It has offered unique opportunity to students and researchers to see a national event that illustrates the basic principles of Mathematics and Physics that are taught in schools and colleges;

- The experience of the solar eclipse can now inspire many scientists and students to study sciences;

- Teachers can use eclipse to show how the law of motion and dynamics of orbital motion can predict the occurrence of eclipses;

- As for the effect on flights, it only gives jolly good cool flight experience - it is more pleasurable than flight in the darkness of a night let alone flying in the cloud;

- The eclipse made Shaki and Kazaure tourist centres, at least, temporarily; 
- Two, three weeks after (and before) the incidence, newspapers, magazines, radio stations and television channels kept on reporting about it and run documentaries on the eclipses, and;

- In Asaba (Delta State Capital) there were life broadcast of the celestial movement on televisions and radio of the brief "dull" weather experienced in the state and environs.

Consequently therefore, it should go down into the history of Nigeria. The location, position and associated events should also remain paramount and documented.

\section{CONCLUSION:}

The Solar Eclipse was a beautiful sight to behold in most parts of the country. Until the experience of March $29^{\text {th }} 2006$, the phenomenon of the celestial bodies, their orbital movements and the concepts of eclipses remained mysteries. To some, God is showing His might; to some others, it was fight between moon and light; others felt, it was an impending rain that threatened to fall, and the rest saw it as a natural orbital movement of the planets. Now, to over $98.75 \%$ of Nigerians it is no longer a mystery. History was made. Probably unaware of the dangers, most people viewed the eclipse without proper eye shield. Whereas, it is best to heed to expert advice. According to the Royal Astronomical Society of Canada (2006) Nigeria will witness a partial lunar eclipse on September 7, 2006 and a yearly Solar Eclipse on September 22, 2006. The last before the March $29^{\text {th }}, 2006$ was in 1947. It has been speculated that the next one should be expected in 34 years time.

Nigerians should not relent to recognize such historic events and document them accordingly. History must be made. Shaki, among other places within the nation had been identified by meteorologist as a vantage point for viewing the 2006 eclipse. But unfortunately the tourist attraction involved was not fully tapped; and the opportunity is not likely to come again until 34 years time when the next Total Eclipse will occur. It is the hope of this paper that by then, those that will live to witness it would have a complete departure from the present attitude 
toward recreation and tourism. A body such as Nigeria Tourism Development Corporation (NTDC) will wake up to its responsibility. The relevant Government Ministries and parastatals should continue to make concerted efforts to educate and enlighten members of the public about such phenomenon. In 34 years time, it is hopped that Television stations, Radio houses, newspapers, magazines and journals of Nigerian origin, research institutions and government and government agencies will be more proactive and prepared to reap the benefits; and properly better document the event. 


\section{REFERENCES:}

Eliot, C (1921) A History of Chinese Philosophy. 3 Vols.

Encyclopaedia Britannica (2004) A world of knowledge at your fingertips.

Encyclopaedia Britannica. Bristol. (Deluxe Edition).

Glover, L.K. et al (1999) National Geographic Encyclopaedia of Space. Washington D.C.

National Geographic pp. 126 - 127

Great Britain National Almanac Office (1977) Explanatory Supplement to the Astronomical Ephemeria and the American Ephemeria and Nautical Almanac. London. Great Britain National Almanac Office.

Green, R.M (1977) Textbook on Spherical Astronomy. Oxford. Oxford University Press. Revised $6^{\text {th }}$ Edition

Link, F. (1969) “Eclipse” Phenomenon in Astronomy. Vol. 21 No 3 pp. 25 - 29.

Menzel, D and Pasachoff, M. (1970) "Solar Eclipse: Nature's Super Spectacular." National Geographic. 138 (2) pp 222 - 233 August.

Mucke, H. and Meeus, J. (1983) Canon of Solar Eclipses -2003 to +2526 and Canon of Lunar eclipses 2002 to +2526 . New York Edward Arnold.

Needham, J. (1959) "Science and Civilization in China" in Mathematics and the Science of the Heavens and the Earth.Vol. 3. Vol. 17 No $2 \& 3$.

Okon - Ekong, N (2006) "Solar Eclipse: Another Tourism Opportunity Lost." This Day. The Sunday News Paper. Lagos. Leader and Company Ltd. (April $\left.2^{\text {nd }}\right)$ pp 85 and 86.

Royal Astronomical Society of Canada (2006) October Handbook of Astronomy Ontario RASC.

Said, S.S. Stephenson, F.R. and Rada, W (1989) "Records of Solar Eclipses in Arabic Chronicles." Bulletin of the School of Oriental and African Studies. Vol. 53 pp. $38-64$

Stephenson, F.R. (1982) "Historical Eclipses" Scientific America. Vol. 247 No 4 pp. 170 - 183 (October). 
Stephenson, F.R. and Said, S.S. (1989) “Non-tidal Changes in the Earth's Rate of

Rotation as Deduced from Medieval Eclipse Observation" Astronomy and Astrophysics. 215 (1) pp $181-189$

This day (2006) "Nigerians Witness Solar Eclipse" in This day (March 2006) pp.2 and 4.

Ukwoma, B. et al (2006) "Excitement As Nigerians Witness Fifth Solar Eclipse" in The Guardian: Conscience Nurtured By Truth. (Thursday $30^{\text {th }}$ March) Lagos. Guardian News Papers Ltd. pp. 1, 2 and 4.

Zachner, R.C. (1961) The Dawn and Twilight of Zoroastrianism. Cambridge. Cambridge University Press. 